\title{
Michael Stausberg, Yuhan Sohrab-Dinshaw Vevaina, Anna Tessmann. The Wiley Blackwell Companion to Zoroastrianism
}

\section{Samra Azarnouche}

\author{
(2) OpenEdition \\ 1 Journals \\ Édition électronique \\ URL : http://journals.openedition.org/abstractairanica/43562 \\ DOI : $10.4000 /$ abstractairanica.43562 \\ ISBN : 1961-960X \\ ISSN : 1961-960X \\ Éditeur : \\ CNRS (UMR 7528 Mondes iraniens et indiens), Éditions de l'IFRI
}

\section{Référence électronique}

Samra Azarnouche, « Michael Stausberg, Yuhan Sohrab-Dinshaw Vevaina, Anna Tessmann. The Wiley Blackwell Companion to Zoroastrianism », Abstracta Iranica [En ligne], Volume 37-38-39 | 2018, document 5, mis en ligne le 30 décembre 2018, consulté le 02 octobre 2020. URL : http://

journals.openedition.org/abstractairanica/43562 ; DOI : https://doi.org/10.4000/abstractairanica 43562

Ce document a été généré automatiquement le 2 octobre 2020.

Tous droits réservés 


\title{
Michael Stausberg, Yuhan Sohrab- Dinshaw Vevaina, Anna Tessmann. The Wiley Blackwell Companion to Zoroastrianism
}

\author{
Samra Azarnouche
}

\section{RÉFÉRENCE}

Michael Stausberg, Yuhan Sohrab-Dinshaw Vevaina, Anna Tessmann. The Wiley Blackwell Companion to Zoroastrianism. Chichester, West Sussex : John Wiley \& Sons, 2015, xxvii + 668 p., bibliographie, index thématique, index locorum.

1 Les trente-trois contributions de ce tout premier Companion sur la religion iranienne rassemblées en près de six années - se répartissent en six grandes parties correspondant aux cadres d'analyse de la recherche contemporaine, qu'ouvre une brève introduction sur le projet du livre et l'histoire de la discipline.

2 1. "Zarathushtra Revisited" se concentre sur la question controversée de la chronologie et la " patrie » d'origine de Zarathshtra (F. Grenet et A. Hintze), la figure de Z. dans les Gāthās à travers les principales interprétations savantes ainsi que dans sa lecture moderne (H. Humbach, J. Kellens, M. Schwartz, P.O. Skjærvø et M. Stausberg). 2. «Periods, Regions, and Contexts» replace la religion dans le contexte politique des Empires pré-islamiques puis sous la domination de l'islam, mais aussi dans des zones non iranophones (Arménie et Géorgie) ou centrasiaques, qui mettent au défi l'idée d'une religion normative (A. de Jong, T. Daryaee, F. Grenet), avant de se concentrer sur le concept de communauté, qu'elle soit parsie, iranienne ou diasporique (J. Hinnells, M. Stasberg), y compris dans les pays de l'Asie de l'est (contribution originale de T. Aoki qui présente aussi un aperçu de l'histoire de la discipline au Japon, en Chine et en Corée). 3. «Structures, Discourses, and Dimensions » rassemble des contributions sur le 
statut et les fonctions des divinités et la manière dont ses éléments prennent leur place dans le discours religieux (théologie et herméneutique), sur la cosmologie, l'astrologie, les mythes et l'eschatologie, sur la question du genre (statut social, rituel et légal de la femme), et sur la loi dans le zoroastrisme pré-moderne et dans sa réinvention parsie (Y. Vevaina, A. Panaino, C. Cereti, M. Macuch, M. Sharafi). 4. «Practices and Sites » rapproche l'éthique de la praxis, en considérant le rite comme l'intervention morale de l'homme dans les évènements du monde, ce qui confère à la prière et au corps de l'homme un rôle central et cosmique. Le temps (calendrier religieux) et le lieu (temples et structures funéraires) sont analysés dans cette perspective (A. Cantera, F. Kotwal, Ph. Kreyenbroek, A. Williams, M. Stausberg, R. Karanjia, J. Rose, J. Choksy). 5. «Intersections » suit une progression chronologique depuis l'héritage indo-iranien de l'Avesta, jusqu'aux contacts avec le judaïsme antique et rabbinique, en traitant aussi des racines du mithraïsme, des interactions des zoroastriens avec les chrétiens, les manichéens et les musulmans, ainsi que des influences visibles dans les croyances yézidies, yârsân et bahaïes (P. Skjærvø, Y. Elman, Sh. Secunda, M. West, R. Gordon, M. Frenschkowski, M. Hutter, Sh. Shaked, Ph. Kreyenbroek, M. Momen). 6. «Primary Sources" est un appendice fournissant une liste descriptive de textes avestiques, pehlevis, persans et gujaratis (peu étudiés jusqu'à présent) et de leurs manuscrits (M. Andrés-Toledo, D. Sheffield).

3 Ce volume indispensable se veut être le reflet de la diversité des écoles et des approches scientifiques autant que de la diversité de la nature de la religion présentée ici comme un réseau complexe et dynamique dont la continuité dépend d'une perpétuelle réinvention.

On notera la discrétion (ou l'absence) de la contribution de l'archéologie et des vestiges matériels, les influences de la philosophie hellénistique sur le discours religieux de l'Antiquité tardive, l'usage controversé des trois termes monothéisme, dualisme et polythéisme, des chapitres sur l'hindouisme et le bouddhisme (commandés mais non reçus par les éditeurs) et enfin, l'usage de plus en plus massif des outils numériques dans la revendication identitaire et la propagande (anti)religieuse.

\section{AUTEURS}

\section{SAMRA AZARNOUCHE}

EPHE, Mondes iranien et indien, Paris 